\title{
Slowing down the corrosion of metal structures using polymeric materials
}

\author{
Fayzulla Nurkulov $^{1 *}$, Umida Ziyamukhamedova ${ }^{2}$, Erkin Rakhmatov $^{2}$, and Jasur Nafasov ${ }^{2}$ \\ ${ }^{1}$ Tashkent Scientific Research Institute of Chemical Technology, Tashkent, Uzbekistan \\ ${ }^{2}$ Tashkent State Transport University, Tashkent, Uzbekistan
}

\begin{abstract}
This article examines the resistance of corrosion-resistant polymeric materials to chemical reagents and the degree of corrosion, taking into account the direction of corrosion processes. One of the main factors that determined the corrosion rate is air humidity and dust released into the atmosphere during industrial emissions. Mixtures based on polymer materials can be used to gum up chemical apparatus and equipment; for corrosion protection, expensive materials are required. The sample is conditioned for 30 months at $(23 \pm 2) 0 \mathrm{C}$, relative humidity $(50 \pm$ 5) $\%$, and the thickness of the sample is determined. Resistance to chemical reagents the change in mass of samples of polymeric materials at a temperature of $35{ }^{\circ} \mathrm{C}$ for 3 months was analyzed. It was also found that by determining the corrosion rate (grade St3) by storing steel plates in a different exposure environment for 50 days. As a result, the corrosion rate of steel anti-corrosion coatings is lower than the control sample. According to the data obtained, it was found that the chloro-sulfonated polyethylene compositions are resistant to various organic solvents, acids, alkalis, oxidizing agents, and others.
\end{abstract}

\section{Introduction}

Corrosion is defined as the destruction of materials caused by chemical or electrochemical action of the surrounding environment. This phenomenon is experienced in day-to-day living. The most common examples of corrosion include rusting, discoloration, and tarnishing [1]. Corrosion is an ever occurring material disease. It can only be reduced. It cannot be prevented because thermodynamically, it is a spontaneous phenomenon.

The reaction of metals with dry air or oxygen is considered chemical corrosion. Hightemperature oxidation of metals and tarnishing of metals like copper, silver, and others fall in this category. Of the late, this is also considered an electrochemical process with the diffusion of oxygen (inwards) and metal ions (outwards) through the oxide layer, the electromotive force at the metal-oxide interface the driving force. Electrochemical corrosion occurs in the presence of electrolytes. The reaction is considered to take place at the metal-solution interface by creating local cathodic and anodic sides on the metal surface $[2]$.

\footnotetext{
*Corresponding author: nfayzulla@mail.ru
} 
The term "atmospheric corrosion" comprises the attack on metal exposed to the air as opposed to metal immersed in a liquid. Atmospheric corrosion is the most prevalent type of corrosion for common metals [3]. Atmospheric corrosion is a subject of global concern because of its importance to the service life of equipment and durability of the structural materials. While there is a general agreement on the possible types of parameters that may lead to corrosion, these studies suffer severely from the lack of generality because their predictive capability is extremely poor.

Conventional atmospheric parameters that may lead to metal corrosion comprise the weathering factors such as temperature, moisture, rainfall, solar radiation, wind velocity, etc. Air pollutants such as Sulphur dioxide, hydrogen sulfide, oxides of nitrogen, chlorides have also been found to contribute to atmospheric corrosion [4]. The complexity and diverse nature of the atmospheric pollutants make the prediction of atmospheric corrosion difficult. The synergistic interaction of the variables must also be considered in the model for arriving at a definite solution. A direct approach to the problem is to measure the observed corrosion rates and the participating atmospheric parameters and correlate them. The correlation equations, thus derived, are known as damage functions, and they have been found to be extremely useful, though in a restricted manner, as the results are not easily transferable from one place to another [5].

Extensive data have been collected worldwide on the atmospheric corrosion of metals exposed at different locations. Empirical and semi-empirical relationships have been developed to generalize these observations. The most prominent of these relationships have been the linear and exponential dependence of corrosion rate with relative humidity, pollutant levels, and temperature [4]. Grossman [6] has investigated the atmospheric factors which determined the time of wetness of the outdoor structures. A thermodynamic perspective of copper tarnishing by $\mathrm{SO}_{2}$ in the presence of moisture was reported by Chawla and Payer [7]. Walters [8,9] carried out some exhaustive studies on the laboratory simulation of atmospheric corrosion by $\mathrm{SO}_{2}$ detailing the apparatus, electrochemical techniques, and example results. The effect of pollutants such as $\mathrm{SO}_{2}, \mathrm{NaCl}$, dust, etc., on the critical humidity for the rusting to occur was well documented by Vassie [10]. A statistical evaluation of the atmospheric corrosion of stainless steel was undertaken by Blank and Lherbier [11]. The atmospheric corrosion rates of mild steel and low alloy cast steels were studied by Thomas and Alderson; Briggs [12,13], respectively. The damage function describing the atmospheric deterioration of materials due to acidic deposition was studied in detail by Lipfert [14].

Loss of material and strength of structural members due to corrosion can have severe consequences in terms of finance, safety, and convenience. Metal corrosion is considered one of the most dangerous types of building structure destruction $[15,16]$. Therefore, the protection of building structures from corrosion is a very topical topic of research, where it is important to decide the correct choice of material for building structures $[17,18]$.

The market offers a wide range of different building materials [19].

Nevertheless, most often, it is metals used for the main load-bearing and roofing structures $[20,21]$. The metal structures choice is determined by their technical advantages: greater precision of manufacture, simplicity, and accuracy of assembly on high-strength bolts, which makes them more advantageous, for example, compared with reinforced concrete structures [22]. However, the lack of steel bearing structures remains to use the need for expensive and labor-intensive anti-corrosion and fire protection measures, warming, and finishing [23]. To select a brand of metals, it is necessary to analyze their properties and their susceptibility to corrosion. 


\section{Methods}

Methods for determining the resistance of polymeric material [24] to the action of chemical media are described below. To determine the resistance of samples to chemicals, as required. The sample is conditioned for 88 hours at $(23 \pm 2) 0 \mathrm{C}$, relative humidity $(50 \pm$ 5) $\%$, and the sample's thickness is determined. For these analyzes of the synthesized polymer material, check the strength for 3 months in various chemicals.

Based on the analysis results by definitions $(\Delta M)$ as a percentage of gain, $\Delta M=(M 1-$ M)*100/M

where $\mathrm{M}$ is the mass of the test sample before its first immersion in a chemical reagent, g;

M1 is mass of the test sample after holding it in a chemical reagent, $g$.

$(\Delta \mathrm{M} 1)$ in percentage (after drying and re-conditioning) weight gain,

$\Delta \mathrm{M} 1=(\mathrm{M}-\mathrm{M} 2) * 100 / \mathrm{M}$

where M2 is sample weight after drying and re-conditioning, $\mathrm{g}$.

$(\Delta \mathrm{L})$ as a percentage, calculate the linear size.

$\Delta \mathrm{L}=(\mathrm{L} 1-\mathrm{L}) * 100 / \mathrm{L}$

where $\mathrm{L}$ is length of dimension before the first immersion of the sample in a chemical reagent, $\mathrm{mm}$;

L1 is length of the size sample after holding it in a chemical reagent, $\mathrm{mm}$.

(D) is diffusion coefficient, (S) is sorption coefficient, $(\mathrm{P})$ is coefficient of permeability determination. GOST 12020-72 Plastics. Methods found that resistance to chemical reagents.

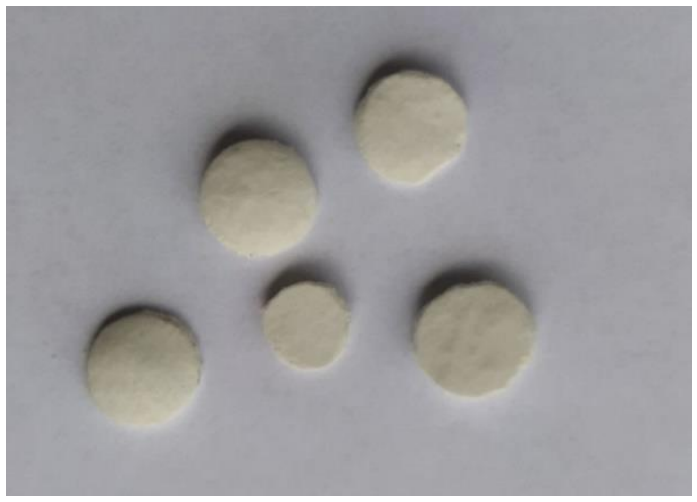

Fig.1. Samples prepared for determination of resistance to chemical reagents

The definition of corrosion conscience applies to coatings (hereinafter referred to as coatings) of surface products and establishes groups, technical requirements, and designations of coatings.
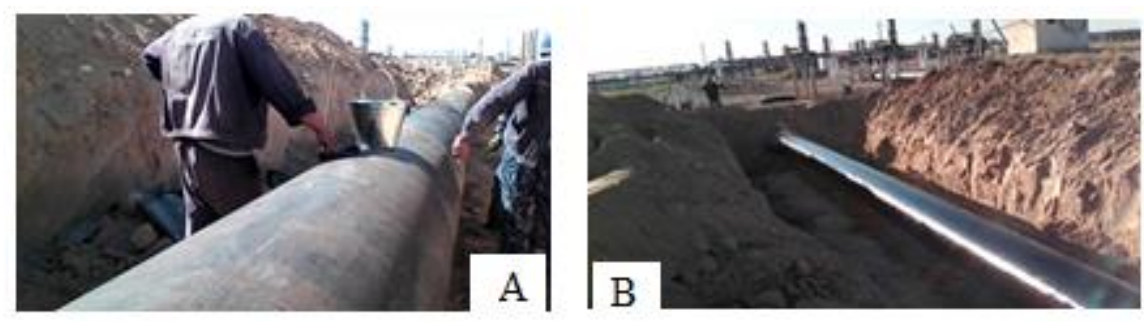
Fig. 2. A. Condition of up to treatment with anti-corrosion coating. B. Condition after treatment with anti-corrosion coating.

The use of polymer composites to protect reinforce concrete and metal pipes from corrosion is of great importance. After applying these polymer composites to a metal surface, they are stored in aqueous solutions of various chemical compounds following the requirements of GOST, and the results are analyzed. GOST 9.602-89 ESZKS. Underground structures. General requirements for corrosion protection

\section{Results and Discussion}

Polymer materials [24, 25] based on composite [26] Chlorosulfonated polyethylene with nitrogen- and phosphorus-containing epoxy resin is well compatible with many anticorrosive polymeric materials while improving their ozone and weather resistance, heat resistance, oil and petrol resistance, fire resistance, adhesion, resistance to water and aggressive environments and increases the overall service life of the polymers.

The level of deformability of crack-resistant, anti-corrosive polymeric materials, and especially coatings based on a chlorosulfonated polyethylene composition in combination with alkali resistance, acid resistance, resistance to oxidizing environments, and heat resistance, allows them to be used as coatings for road construction and building structures $[24,26]$. Particularly effective is the use of such highly elastic anti-corrosive polymeric materials for the protection of thin-walled structures that undergo deformations during operation due to temperature extremes or vibration, as a result of which, as is known, conventional harsh chemically resistant paints and varnishes (epoxy, perchlorovinyl, etc.) very quickly come out out of service.

Of particular interest is the use of a chlorosulfonated polyethylene composition for combating corrosion. Mixtures based on polymer materials can be used to gum up chemical apparatus and equipment; for corrosion protection, the use of expensive materials is required.

The sample is conditioned for 88 hours at $(23 \pm 2) 0 \mathrm{C}$, relative humidity $(50 \pm 5) \%$, and the sample's thickness is determined. The change in the mass of the samples in different environments is given in Table 1. 
Table 1. Change in the mass of samples of polymer materials in different environments at $350 \mathrm{C}$ for 3 months

\begin{tabular}{|c|c|c|c|c|c|c|}
\hline \multicolumn{2}{|c|}{ Liquid chemical reagents } & \multirow{2}{*}{ Indicators } & \multicolumn{3}{|c|}{ Exposure of CSPE in aggressive environments, } \\
months
\end{tabular}

From the obtained results $\Delta \mathrm{M}$ and $\Delta \mathrm{M} 1$ polymer material in chemical solutions table- 1 . Polymeric material in chemical solutions under No. (2), within 1-2 months, has a very high swelling capacity. Then, within the 3rd month, the swelling capacity of the polymeric material passed into a stable state. And for polymer material in chemical solutions under No. (1.5) within 1-2 months, swelling manifested itself partially, then within the 3rd month, it passed into a stable state. Polymer material in chemicals under No. $(3,4,6)$ partially is decomposed within 1 month and then passed into a stable state (Table 1.). Preliminary tests of the polymer material have shown that it is superior to some industrial elastomers, such as 
chlorinated rubber, polyvinyl chloride, and others, in terms of resistance to acids and corrosive environments.

The anti-corrosive polymer material used for metal structures is a substance that protects metal surfaces from corrosion. The mechanism of the anti-corrosive effect on metals, primarily on steel, is that an anti-corrosive polymer material coating is applied to the metal surface (grade St3), consisting of a film with a total thickness at least $2.0 \mathrm{~mm}$, which protects the metal from corrosion.

The temperature of the test medium was maintained at 25-10C. From the results obtained below, the curves of the samples were obtained, where it is possible to determine the protective ability of the corrosion inhibitor.

The protective ability was determined by keeping steel plates (grade St3) in different aggressive environments for 50 days. The table shows that the degree of corrosion of steel applied anti-corrosion coatings is less than that of the control sample. For testing, we have prepared samples based on the following products: Compositions of chlorosulfonated polyethylene with nitrogen and phosphorus-containing epoxy resin.

Table 2. Results of gravimetric determination of the degree of protection anti-corrosion coating

\begin{tabular}{|c|c|c|c|c|}
\hline \multirow{2}{*}{ № } & Test environment & Indicators & $\begin{array}{c}\text { The control } \\
\text { sample }\end{array}$ & $\begin{array}{c}\text { Anti-corrosive } \\
\text { polymer material }\end{array}$ \\
\hline \multirow{2}{*}{1} & \multirow{2}{*}{$\mathrm{H}_{2} \mathrm{O}$} & $\mathrm{K}$ & 0.0012 & 0.000003 \\
\cline { 3 - 5 } & & $\mathrm{Z}$ & - & 99.7 \\
\hline 2 & \multirow{2}{*}{$\mathrm{NaCl} 5 \%$} & $\mathrm{~K}$ & 0.0059 & 0.000069 \\
\cline { 3 - 5 } & & $\mathrm{Z}$ & - & 98.8 \\
\hline \multirow{2}{*}{3} & $\mathrm{Na}_{2} \mathrm{CO}_{3} 5 \%$ & $\mathrm{~K}$ & 0.0061 & 0.00060 \\
\cline { 3 - 5 } & & $\mathrm{Z}$ & - & 90.2 \\
\hline 4 & $\mathrm{Na}_{2} \mathrm{SO}_{4} 5 \%$ & $\mathrm{~K}$ & 0.0049 & 0.000061 \\
\cline { 3 - 5 } & & $\mathrm{Z}$ & - & 98.7 \\
\hline 5 & $\mathrm{Na}_{2} \mathrm{~S}_{5} \%$ & $\mathrm{~K}$ & 0.0060 & 0.00031 \\
\cline { 3 - 5 } & & $\mathrm{Z}$ & - & 94.8 \\
\hline 6 & $\mathrm{NaHCO}_{3} 5 \%$ & $\mathrm{~K}$ & 0.0057 & 0.000058 \\
\cline { 3 - 5 } & & $\mathrm{Z}$ & - & 99.8 \\
\hline 7 & $\mathrm{CaCO}_{3} 5 \%$ & $\mathrm{~K}$ & 0.0029 & 0.000030 \\
\cline { 3 - 5 } & & $Z$ & - & 98.9 \\
\hline
\end{tabular}

$K,\left(\mathrm{~g} / \mathrm{cm}^{2}\right.$ day) is corrosion rate; $Z \%$, is degree of protection.

Anti-corrosion coating has sufficiently high corrosion-resistant properties to protect concrete, metal, and other materials from aggressive chemical influences.

\section{Conclusions}

1. In this work, we studied the factors affecting metal structures.

2. According to the study results, the resistance of anti-corrosion polymeric materials that protect metal structures from corrosion, solvents, acids, and salts, as well as the degree of protection of metal surfaces from corrosion is more than $90 \%$.

3. Polymer materials, based on a chloro-sulfonated polyethylene composition, can be used in the production of anti-corrosion coatings, can be recommended for road construction, building structures and materials, as film-forming paints and varnishes that protect the wood, metal, reinforced concrete, etc., as well as how the base of anticorrosion coating. 


\section{References}

1. F. N. Speller, Corrosion-Causes and Prevention, McGraw-Hil (New York, 1951)

2. T. P. Evans, U.R., Hoar, Proc. R. Soc. London. Ser. A, Contain. Pap. a Math. Phys. Character 137, p 343. (1932).

3. N. Xu, L. Zhao, C. Ding, C. Zhang, R. Li, and Q. Zhong, Corros. Sci. 44, p 163. (2002).

4. P. W. Brown and L. W. Masters, in Atmos. Corros, pp. 31-49. (1980)

5. J. C. Scully, The Fundamentals of Corrosion 3rd Edn. (Pergamon Press, Oxford; New York:, 1990)

6. P. . Grossman, Atmospheric Factors Affecting Engineering Metals, (1987).

7. S. K. Chawla and J. H. Payer, Corrosion 46, p 860 (1990)

8. G. W. Walter, Corros. Sci. 32, p.1353. (1991).

9. G. W. Walter, Corros. Sci. 32, p.1331. (1991).

10. P. R. Vassie, Br. Corros. J. 22, p 37, (1987).

11. H. Black and L. Lherbier, in Met. Corros. Atmos., pp. 3-3-30, (2009),

12. H. Thomas and H. Alderson, in Met. Corros. Atmos., pp. 83-83-12. (2009).

13. C. Briggs, in Met. Corros. Atmos. (2009), pp. 271-271-14

14. F. W. Lipfert, Mater. Perform. 26, p 12. (1987).

15. M. H. Al-Sherrawi, V. Lyashenko, E. M. Edaan, and S. Sotnik, Int. J. Civ. Eng. Technol. 9, (2018)

16. A. Lyons, Materials for Architects and Builders (Routledge, 2014)

17. V. Lyashenko, M. A. Ahmad, S. Sotnik, Z. Deineko, and A. Khan, Int. J. Mech. Prod. Eng. Res. Dev. 8, (2018).

18. D. R. T. David E.J. Talbot, James, Corrosion Science and Technology, Third Edition (CRC Press, 2018).

19. J. M. Khatib, Sustainability of Construction Materials (2009).

20. O. Kuzomin, M. A. Ahmad, H. Kots, V. Lyashenko, and M. Tkachenko, Int. J. Civ. Eng. Technol. (7), (2016)

21. M. A. El-Reedy, Steel-Reinforced Concrete Structures: Assessment and Repair of Corrosion, Second Edition (2017).

22. F. D. Ching and M. Mulville, European Building Construction Illustrated (2014).

23. R. Matarneh, S. Maksymova, Z. Deineko, and V. Lyashenko, Int. J. Civ. Eng. Technol. 8, (2017).

24. U. A. Ziyamukhamedova, L. Y. Bakirov, E. A. Rakhmatov, and B. S. Bektemirov, Int. J. Recent Technol. Eng. 8, (2019).

25. N. S. Negmatov, U. A. Ziyamukhamedova, and A. R. Kuluev, Plast. Massy Sint. Svojstva Pererab. Primen. (2002).

26. F. N. Djalilov, A.T., Nurkulov, (2015). 